\title{
Debaryomyces hansenii Is a Real Tool to Improve a Diversity of Characteristics in Sausages and Dry-Meat Products
}

\author{
Laura Ramos-Moreno, Francisco Ruiz-Pérez (), Elisa Rodríguez-Castro and José Ramos * \\ Agriculture Microbiology Research Group, Department of Agricultural Chemistry, Edaphology and Microbiology, \\ University of Córdoba, E-14071 Córdoba, Spain; lauraramosm89@gmail.com (L.R.-M.); b42rupef@uco.es (F.R.-P.); \\ q72rocae@uco.es (E.R.-C.) \\ * Correspondence: mi1raruj@uco.es; Tel.: +34-957212527
}

Citation: Ramos-Moreno, L.; Ruiz-Pérez, F.; Rodríguez-Castro, E.; Ramos, J. Debaryomyces hansenii Is a Real Tool to Improve a Diversity of Characteristics in Sausages and Dry-Meat Products. Microorganisms 2021, 9, 1512. https://doi.org/ $10.3390 /$ microorganisms 9071512

Academic Editor: Elia Tomás Pejó

Received: 28 June 2021

Accepted: 14 July 2021

Published: 15 July 2021

Publisher's Note: MDPI stays neutral with regard to jurisdictional claims in published maps and institutional affiliations.

Copyright: (c) 2021 by the authors. Licensee MDPI, Basel, Switzerland. This article is an open access article distributed under the terms and conditions of the Creative Commons Attribution (CC BY) license (https:/ / creativecommons.org/licenses/by/ $4.0 /)$.

\begin{abstract}
Debaryomyces hansenii yeast represents a promising target for basic and applied biotechnological research It is known that $D$. hansenii is abundant in sausages and dry-meat products, but information regarding its contribution to their characteristics is blurry and contradictory. The main goal in this review was to define the biological contribution of $D$. hansenii to the final features of these products. Depending on multiple factors, $D$. hansenii may affect diverse physicochemical characteristics of meat products. However, there is general agreement about the significant generation of volatile and aromatic compounds caused by the metabolic activities of this yeast, which consequently provide a tendency for improved consumer acceptance. We also summarize current evidence highlighting that it is not possible to predict what the results would be after the inoculation of a meat product with a selected D. hansenii strain without a pivotal previous study. The use of $D$. hansenii as a biocontrol agent and to manufacture new meat products by decreasing preservatives are examples of exploring research lines that will complement current knowledge and contribute to prepare new and more ecological products.
\end{abstract}

Keywords: Debaryomyces hansenii; yeast; sausages; dry-meat products; starter cultures

\section{Introduction}

The microbiome of sausages and dry-meat products is an important factor contributing to the characteristics of these foods. Lactic acid bacteria and some micrococci and staphylococci are predominant groups of prokaryotic microorganisms found in fermented sausages that play an important role in the fermentative process and ripening. In fact, the role of bacteria in the manufacture of meat products is quite well known compared with that of yeast [1-5] since, in many cases, although several yeast have been isolated and identified their function has not yet been studied. Multiple reports on the diversity of yeast populations in sausages and other dry-meat products have indicated that $D e$ baryomyces hansenii is one of the most abundant and commonly found species in these products [6-10]. However, there is not complete agreement about the real importance of $D$. hansenii in the ripening and final characteristics of these foods, and controversial results are available in literature concerning its effects on the quality and/or sensory characteristics of fermented meat products. Therefore, the influence of D. hansenii on the quality and/or sensory characteristics of fermented meat products has not been completely defined.

In general, the contribution of yeast populations to flavour and aroma in meat products is usually related to their ability to ferment sugars and to degrade amino acids, consequently producing ethanol, acetaldehyde, or ethyl acetate, as well as a variety of other volatile compounds [11]. Moreover, yeast also metabolizes lactic acid produced by lactic bacteria, thus affecting the organoleptic characteristics of the product. However, it is important to note that other yeast genera such as Rhodotorula, Yarrowia, Candida, Trichosporon, Citeromyces, Kazachstania, or Wickerhamomyces are commonly present in meat products and that flavour and aroma changes cannot be solely attributed to Debaryomyces [9,12-16]. In addition, a 
pertinent question is whether changes in the products due to the yeast populations can be finally perceived by the consumer and affect the overall sensory characteristics of the products.

Published information on the functions of Debaryomyces is confusing, blurry, and sometimes even contradictory, probably due to the fact that $D$. hansenii is a highly heterogeneous species with wide phenotypic differences and is sometimes miss-identified [17]. Naturally occurring strains are supposed to improve products, however there is no general conclusion regarding the consequences of the inoculation of meat products with $D$. hansenii. Therefore, it is difficult to predict positive effects on the final products.

The main issue addressed in this work is to define the biological importance of $D$. hansenii in the preparation of sausages and dry-meat products independently of the specific manufacturing characteristics of the different foods. The specific objectives of this review are to: (i) contribute to unravelling and deciphering the real importance of the presence of $D$. hansenii in meat products; and (ii) to analyse the expectations created about the use of $D$. hansenii in other novel aspects of research, such as the reduction in the use of preservatives or its potential role as a biocontrol agent.

\section{Debaryomyces hansenii as a Non-Conventional Yeast of Biotechnological Importance}

Debaryomyces hansenii is a hemiascomycetous yeast of undoubted biotechnological importance [18]. It is a heterogeneous yeast species able to grow under extreme conditions, such as high salt or relatively alkaline $\mathrm{pH}$ levels. This yeast has high respiratory and low fermentative activity [19]. It ferments with important variations, depending on the strain and growth conditions used [20,21]. Briefly, some examples of its beneficial effects are the production of xylitol [22], lipases, and exopeptidases important in the food industry, and of thermophilic $\beta$-glucosidases essential to produce fuel alcohol [18]. Moreover, it is considered as a model of eukaryotic microorganism for the study of osmotic adaptations and salt tolerance. It can grow in the presence of different carbon sources and produces killer toxins $[17,18]$. Very interestingly, D. hansenii seems to have the highest coding capacity amongst yeasts [23]. This microorganism colonizes a great diversity of specific microhabitats, indicating the existence of yeast subpopulations adapted to such habitats and showing chromosomal polymorphism. In this way, it has been reported that specific probes can be useful to investigate biodiversity within D. hansenii [24].

Despite the potential of this yeast, different circumstances have hindered its habitual scientific and biotechnological use and have prevented the further development of its industrial applications $[17,18]$. Linked to its heterogeneous diversity, there is also some confusion regarding its negative effects to human health. Since the early 1980s D. hansenii has been assimilated with other species as Candida famata, which has been considered its clinically anamorph. These identifications were mainly based on inaccurate phenotypic characteristics that are now being questioned. As a consequence of the difficulties related to separating $D$. hansenii from closely related yeasts, a diversity of biochemical and molecular approaches are currently in use to clearly identify this species [24-29]. Once again, several reports using molecular tools to discriminate between species have described the misidentification of Pichia guilliermondii and others as D. hansenii/C. famata [30-32]. Furthermore, some of the previously identified C. famata strains have now been included in other Debaryomyces-related species such as D. fabryi or Candida flareri [33]. Although $D$. hansenii is closely related to Candida and some authors have reported D. hansenii as an emergent pathogen, so far, no clear clinical significance has been attributed to this yeast and therefore it is not responsible for generalized or common health problems, and we can conclude that it is not relevant from a clinical point of view. Altogether, these studies suggest that D. hansenii may be a very rare (or even non-existent) human pathogen.

The lack of user-friendly molecular tools to manipulate this yeast has slowed the research on $D$. hansenii; in addition, the fact that $D$. hansenii is not clinically significant could also be considered as a factor for its research disinvestment [30]. For example, the number of well-characterized genes/proteins from $D$. hansenii is still very low and limited 
to a few families. Finally, it is worth noting that D. hansenii belongs to the ambiguous CUG decoding group of yeasts, in which CUG codon can be ambiguously translated, mainly as serine but also as leucine, although in a minor percentage [34].

\section{Debaryomyces hansenii Is One of the Most Abundant Yeasts in Sausages and Dry-Meat Products}

The usual approach to the study of the microbiome present in dry-meat food and sausages is the isolation and identification of the main populations present in these products. In this way, yeast isolates have been obtained from many different meat products during the last decades. Although their functions and effects in meat were not always defined in detail, there is no doubt that previous studies demonstrate that Debaryomyces hansenii is frequently and abundantly found in sausages and dry-meat products [6-9,29].

The identification of $D$. hansenii as the most common yeast in salami was made as early as 1954 [35]. Since then, and especially in the last two decades, the presence of multiple strains of $D$. hansenii in sausages and dry-meat products has been reported. Table 1 summarizes some of these products and their origins. Many countries where sausages and dry-meat foods have been studied belong to the Mediterranean area [8,36-41], but dry-cured meat or sausages are prepared and consumed by millions of people worldwide and also in other European countries such as Denmark [42], Norway [43], Austria [7], the United Kingdom [6], and Portugal [44]. Even in places such as Argentina [45] or China $[46,47]$, among many others, meat products are manufactured in which it is possible to find D. hansenii yeasts, supposedly contributing to the final organoleptic characteristics of the food.

Table 1. A selection of sausages and dry-meat products from which Debaryomyces hansenii has been isolated.

\begin{tabular}{|c|c|c|c|}
\hline Product & Origin & Brief Description & References \\
\hline “Cacholeira" & Portugal & $\begin{array}{l}\text { Traditional Portuguese sausage with delicate flavour obtained } \\
\text { from the offal and fat of the pig. }\end{array}$ & [44] \\
\hline “Chorizo" & Spain & $\begin{array}{l}\text { Traditional Spanish cured meat product made from coarsely } \\
\text { chopped pork and pork fat seasoned with garlic, "pimentón", } \\
\text { and salt. }\end{array}$ & [5] \\
\hline “Jamón ibérico" & Spain & $\begin{array}{c}\text { High-quality variety of "jamón" produced in Spain and } \\
\text { Portugal. }\end{array}$ & {$[37,40]$} \\
\hline "Jamón" & Spain & Meat product from pork typical of Spanish cuisine & [48] \\
\hline “Lacón” & Spain & $\begin{array}{l}\text { Cured meat product obtained from the shoulders or front legs } \\
\text { of the pig. }\end{array}$ & [49] \\
\hline "Salame di senise" & Italy & $\begin{array}{c}\text { Traditional dry sausage from the Sinni Valley in the Basilicata } \\
\text { region. }\end{array}$ & [38] \\
\hline “Salchichón” & Spain & $\begin{array}{l}\text { Traditional Spanish cured meat generally made of pig, although } \\
\text { other meats can be used. }\end{array}$ & {$[29,50]$} \\
\hline "Salsicca sarda" & Italy & $\begin{array}{l}\text { Traditional fermented dry-cured sausage produced exclusively } \\
\text { in Sardinia. }\end{array}$ & [51] \\
\hline $\begin{array}{l}\text { "Soppressata of Vallo di } \\
\text { Diano" }\end{array}$ & Italy & Traditional Southern Italian dry-fermented sausage. & [52] \\
\hline "Sucuck" & Turkey & $\begin{array}{l}\text { Semi-dry, spicy Middle Eastern sausage with a high fat content } \\
\text { traditionally prepared with ground beef and spices. }\end{array}$ & [39] \\
\hline Dry-cured Parma ham & Italy & Famous variety of "prosciutto" from the Parma region in Italy. & [53] \\
\hline Fermented sausage & $\begin{array}{c}\text { Norway; } \\
\text { Denmark; Italy; } \\
\text { United } \\
\text { Kingdom; } \\
\text { Spain }\end{array}$ & Diverse kind of fermented meat. & {$[8,13,42,54,55]$} \\
\hline
\end{tabular}


Table 1. Cont.

\begin{tabular}{|c|c|c|c|}
\hline Product & Origin & Brief Description & References \\
\hline Greek dry salami & Greece & Traditional Greek dry-cured meat. & [36] \\
\hline Laowo dry-cured ham & China & $\begin{array}{c}\text { Traditional Chinese dry-cured ham obtained from the hind leg } \\
\text { of the pig. }\end{array}$ & [46] \\
\hline Llama meat sausage & Argentina & $\begin{array}{l}\text { Traditional products consumed in the Andrea region of South } \\
\text { America. }\end{array}$ & [45] \\
\hline Mianning ham & China & $\begin{array}{l}\text { Traditional fermented meat product in Meanning, characterized } \\
\text { by the use of plump muscle and small legs. }\end{array}$ & [10] \\
\hline Panxian ham & China & $\begin{array}{l}\text { Famous dry-cured ham in China characterized by strong taste, } \\
\text { flavour, aroma, and texture. }\end{array}$ & {$[47]$} \\
\hline Pork loin & Spain & $\begin{array}{l}\text { Cured meat product prepared by removing fat from pork } \\
\text { followed by seasoning for six months. }\end{array}$ & [56-58] \\
\hline Vienna sausage & Austria & $\begin{array}{l}\text { Thin, parboiled sausage traditionally made of pork and beef in } \\
\text { a casing of sheep's intestine. }\end{array}$ & [7] \\
\hline
\end{tabular}

As already mentioned, the very diverse metabolic discrepancies of $D$. hansenii have been observed in naturally occurring strains isolated from the same meat products. For example, differences in the capacity to assimilate xylose [8,59], in the urease activity [8] or in specific lipolytic and proteolytic enzymatic activities [29], have been reported. However, several groups have obtained similar qualitative results coincident when describing some important physicochemical characteristics in $D$. hansenii isolates from different origins. For example, a high resistance to $\mathrm{NaCl}$ or the sensitivity to relatively high temperatures $\left(37^{\circ} \mathrm{C}\right)$ have been usually observed in D. hansenii strains found in sausages from Italy or Spain $[8,29]$.

From the different studies reporting on yeast populations in sausages and dry-cured meat products, it can be deduced that even the behaviour of the yeast populations during the ripening of the dry-meat products do not seem to be homogeneous. Thus, while a microbiological study of Greek salami reported that yeasts did not significantly increase in the ripened product (after 28 days) [60], the yeast counts in sausages of southern Italy significantly increased during the first days of fermentation, subsequently remaining constant or even decreasing [8]. As a final example and in the case of dry-cured Iberian ham, higher counts of yeast were reached at post-salting or at drying periods and then the number decreased after several months in a cellar [37]. In any case, and independently of the manufacturing process, naturally occurring yeasts are usually found in high numbers indicating that these microorganisms may play an important role in the maturation process [50]. Therefore, it is generally accepted that the yeast populations, including $D$. hansenii, present in artisanal-style products contribute to flavour, colour, and texture development during the ripening of these products. However, the presence of competing bacteria, mostly lactic acid bacteria, and other organisms has made it difficult to reach solid conclusions about the functions and contributions of specific species. That is why most of these studies have focussed their attention on quantifying, identifying, or partially characterizing yeast species during the manufacturing process and/or the maturation period $[8,13,15,29]$. Very recently some research groups have used "omic" and multidisciplinary approaches to analyse the microorganisms during processing or ripening in traditional Chinese products $[46,47]$. Bacteria and fungi were identified, for example during panxian ham processing, a traditional Chinese dry-cured ham, and it was concluded that Staphylococcus, Chromohalobacter, and Debaryomyces promoted the production of amino and fatty acids [47], but once again the presence of naturally occurring complex communities made it difficult to reach more specific conclusions.

In summary, $D$. hansenii is naturally present in significant numbers in many different dry-meat products and sausages, however it is difficult to isolate its role in final organoleptic 
characteristics mainly due to the presence of other populations of microorganisms that also influence the maturation of the product. Therefore, the inoculation of high amounts of $D$. hansenii as a sole starter is the next in an attempt to unravel the effects this yeast has on dry-meat products by comparison with control batches containing only their natural microbiome.

\section{Debaryomyces hansenii as a Starter Culture: Effects on the Final Characteristics of Meat Products}

How Debaryomyces hansenii activity effects the organoleptic properties and appearance of sausages and dry-meat products has not been sufficiently clarified. The contributions of yeast to the final characteristics of these products can be related to its ability to ferment different sugars, to degrade peroxides and amino acids, and to its lipolytic activity [11,61-63]. Several research groups have approached many of these issues from different points of view and under diverse conditions. The use of D. hansenii as a starter culture, through the inoculation of high amounts of a specific strain, can undoubtably help to understand the role of this species during ripening and the consequences of its presence. The group of $\mathrm{M}$. Flores, for example, has very actively analysed the impact of $D$. hansenii strains on meat products in the presence of low salt or by manufacturing sausages with entirely male fat [64-66]. It is important to keep in mind that, as mentioned below, some papers report the use of pure $D$. hansenii starters while some others use the yeast in combination with additional microorganisms which must be considered in order to reach conclusions $[54,67,68]$.

We summarize below some of the main changes in meat products that have been reported to be induced by the presence of $D$. hansenii.

\subsection{Lipolysis}

D. hansenii shows lipolytic activity. In 1997 it was shown that a commercial starter of this yeast could hydrolyse a natural fatty substrate like pork fat and release fatty acids. In this case, lipolysis caused by $D$. hansenii was not affected by $\mathrm{NaCl}$ (most probably due to the salt-tolerant character of this yeast) and it was still significant at $\mathrm{pH} 4.7$, indicating that this commercially available starter culture may hydrolyse pork fat during the processing of fermented meat products [69].

Later, our group has shown that the lipase activity of several strains isolated from Iberian dry-meat products greatly differed among strains, furthermore it was always higher than the corresponding activity in a control laboratory strain (CBS767) [29].

More recently, we used a selected terroir strain isolated from pork loin, D. hansenii $\operatorname{Lr} 1$, to inoculate different amounts of yeast either directly onto the meat surface or onto the collagen casing in which each loin piece was stuffed to make the product. Possible changes in the lipid profile of the loins were determined. In all cases, including control samples, loins contained a very low percentage of polyunsaturated fatty acids (PUFAs) and the most abundant were monounsaturated fatty acids (MUFAs). On the other hand, inoculation with the Lr1 strain did not significantly change the fatty acid profiles of any of the treatments applied. Within all the samples, oleic acid (C18:1) constituted around 50\%, palmitic acid (C16:0) around $26 \%$, and stearic acid (C18:0) around $10-12 \%$ of the total fatty acids. Clear differences could not be found related to the different treatments and only slight, although consistent, effects on the percentage of some fatty acids were observed as, for example, all the treatments showed a decrease in the percentage of t-oleic acid (elaidic acid, C18:1 n9t) when compared to the control samples. In summary, it was shown that inoculation with the D. hansenii Lr1 strain did not significantly change the global lipid profile of the loins. Only the amounts of some fatty acids were affected, however changes in the total amounts of saturated fatty acids (SFA), MUFAs, and PUFAs were not significant [58].

However, a different study showed that the generation of free fatty acids during sausage fermentation is affected by yeast inoculation. In this case, the D. hansenii P2 strain, previously isolated from naturally fermented sausages "salchichón de Requena [54,70], was inoculated in sausages manufactured with boar back fat or with gilt back fat. It was demonstrated that inoculated sausages had a higher degree of lipolysis and that this was 
strongly dependent on the ripening time and the conditions. After 63 days of ripening, an increase in the content of free MUFAs, PUFAs, and total free fatty acids was measured in the boar sausages while, in general, lower, or even no significant differences, were observed after 43 days of ripening or when the sausages were manufactured using gilt back fat instead of boar back fat. The authors concluded that environmental conditions affect lipase activity or lipase expression genes, potentially explaining differences between strains or products [66].

In summary, experimental evidence suggests that the inoculation of dry-meat products with $D$. hansenii can affect their lipid profile but that this does not seem to be pivotal to the outcome, and, in any case, it depends on multiple factors that may mask and/or alter the specific effect of the yeast.

\subsection{Volatile Compounds}

A generally accepted idea is that the generation of volatile compounds by D. hansenii is one of the most important contributions to the ripening process in dry-meat products. It is usually found that the introduction of $D$. hansenii as a starter culture affects volatile and aromatic compound generation. Among them, esters are essential contributors to the aroma of meat products due to their low detection threshold and sensory notes. The production of these compounds represents a complex scenario and it is strongly dependent on the different isolates and strains and even on the amount of yeast used [54,55]. In fact, production of volatile sulphur compounds from sulphur amino acids greatly varied among $D$. hansenii strains isolated from different food sources and the generation of, at least, some of these compounds could result from yeast metabolism [71].

Several groups have used starter cultures containing Debaryomyces in combination with other different microorganisms. For example, when dry-fermented sausages were inoculated with Debaryomyces spp. plus lactic acid bacteria and staphylococci, it was concluded that the use of this combination of microorganisms had a positive effect on the final flavour and sensory qualities of the product influenced by the generation of ethyl esters [72]. Importantly, the authors found that the amount of yeast used in the starter culture must be optimised, since too many yeasts may mask some positive effects. More recently, a similar approach was followed to study the effects of different starter cultures on volatile compounds of dry-cured foal sausages. In this case, three different starters were used and while two of them contained only bacteria, the third one was prepared with bacteria (Lactobacillus sakei, Staphylococcus carnosus, and Staphylococcus xylosus) and yeast (D. hansenii). Significantly different effects on the volatile compounds or acid taste were found among the different batches, with the batch containing $D$. hansenii showing a high flavour intensity and high levels of compounds derived from carbohydrate fermentation and amino acid catabolism [73]. The use of mixed starters containing only fungi has been less frequent. When Penicillium chrysogenum and D. hansenii were inoculated on dry-cured ham they did not remarkably alter the volatile compound profile. Only lower levels for some of the main odour-active volatile compounds were measured but they were not detected by a panel of experts [48].

Evidently, conclusions about the specific contributions of $D$. hansenii must be analysed from a global point of view, since all these experiments were performed with mixed starter cultures. Due to the difficulties surrounding the proper interpretation of the results obtained in these types of experiments, many other groups have focused on the use of pure D. hansenii starters $[42,49,50,58]$.

One of the first realistic attempts to understand the specific effect of $D$. hansenii on aroma formation was performed by Olesen and Stahnke [42] in spiced fermented sausages. It was found that $D$. hansenii had very little effect with the analysis showing only a slight difference between the inoculated sausages and the control, possibly due to the fact that the yeast died out before the ripening process ended. The main reason was that sausages were spiced with garlic, and a fungistatic test of the garlic powder added to the sausages indicated that garlic inhibited the growth of the yeast starter cultures [42]. 
Later studies showed that $D$. hansenii contributes to the development of the characteristic flavour of some of these dry-meat products $[49,50,58]$. A research conducted on the dry-fermented sausage "salchichón" and performed with different D. hansenii strains indicated that the inoculation of selected isolates may have a positive contribution to the volatile compound generation involved in the flavour development of this meat product. In this study, yeasts were incorporated into the batches and the mixture of each batch was stuffed into regenerated collagen casings. The tested yeast strains promoted the generating of esters, alcohols, and aldehydes, and some volatile compounds derived from lipid oxidation [50]. In addition, when the effect of D. hansenii on dry-cured "lacon" and Iberian cured pork loin ("lomo ibérico") was studied, similar approaches were followed: strains were selected from native products and used as starters. Yeasts were spread on the surface of the meat product and their capacity to generate volatile compounds was determined. Figure 1 shows the proliferation of inoculated $D$. hansenii on the surface of pork loin during the ripening period. As expected, quantitative differences were found when both studies were compared. This is not surprising, since both strains and meat products were different. Nonetheless, important qualitative similarities were found. In all cases, and in agreement with previous work in "salchichón", D. hansenii modified the levels of volatile and aromatic compounds by increasing esters and alcohol metabolites in comparison to the non-inoculated samples $[49,58]$. However, and in contrast with what was reported in the case of "salchichón", a significant decrease in aldehydes was reported in both "lacon" and "lomo ibérico".

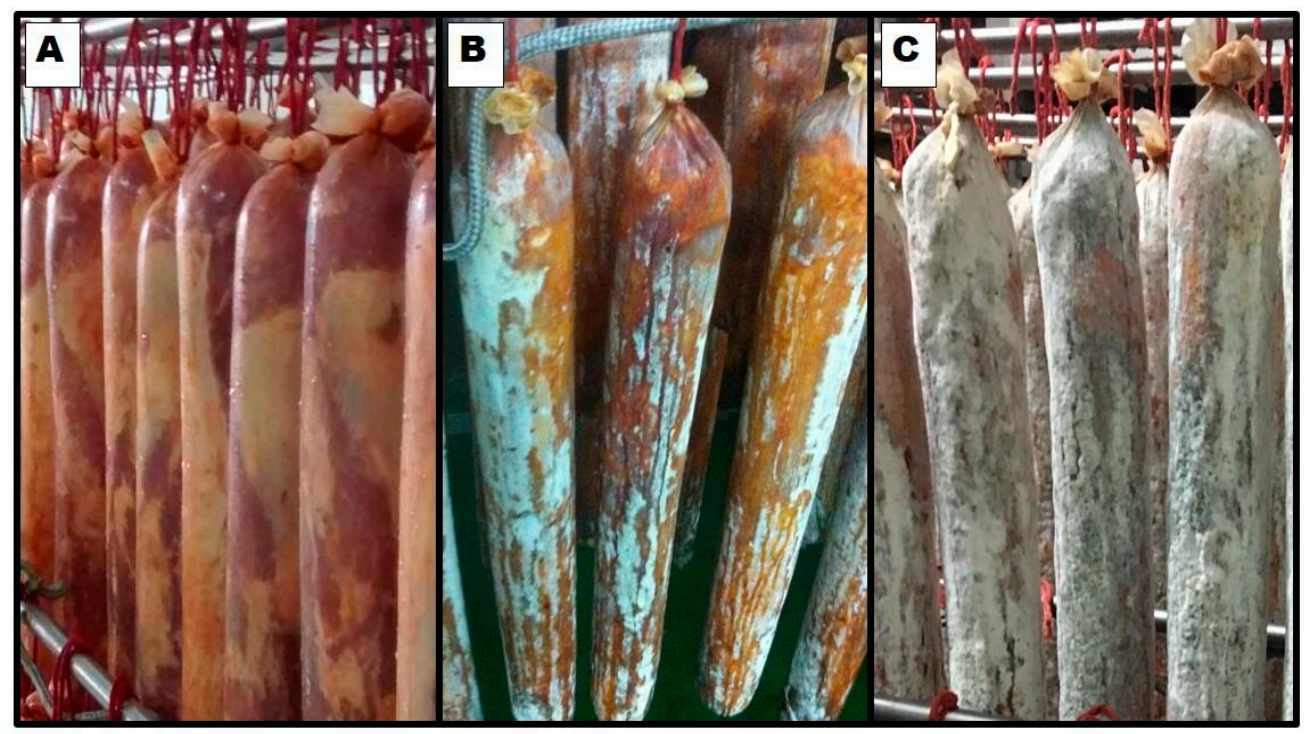

Figure 1. Implantation of inoculated Debaryomyces hansenii yeasts on the surface of pork loins after 0 (A), 10 (B), and $30(\mathbf{C})$ days of ripening.

In some cases, a different approach was followed, since model minced meats which did not correspond to any specific commercial meat products were used. A first attempt by Olesen and Stahnke [42] indicated that the use of D. hansenii as a starter culture had very little effect on the production of volatile compounds in the model minces, although, as previously mentioned, the presence of garlic affected cell viability. More recently, the ability of several $D$. hansenii strains to generate aromas in a fermented sausage model system was evaluated. The performance of seven different strains previously selected on their ability to produce aromatic compounds in a defined culture media [70] were later studied in a meat model system. The presence of each inoculated strain was confirmed in the model system and an increase in volatile compound production was observed in all cases. However, significant differences were found among strains, especially in relation to ester production which was correlated to the lipolytic activity of the strains. Sulphur 
production was also strongly dependent on the inoculated strain. In summary, it was concluded that: (i) the inoculated D. hansenii strains affected the flavour development of the meat model system; (ii) wide differences do exist among strains, although in all cases volatile compounds increased; (iii) the meat model system is useful to show the ability of $D$. hansenii strains to produce aromatic compounds; and that (iiii) it is necessary to investigate the effects of specific strains in real dry-fermented sausages [54,55].

Finally, in a more complex study and working with dry-fermented sausages manufactured with reduced salt content and several types of fats, again the production of aldehydes was reduced while the production of alcohols and esters was increased in the presence of D. hansenii [66].

\subsection{Other Physicochemical and Sensory Characteristics Affected by Debaryomyces hansenii 4.3.1. $\mathrm{pH}$}

Several studies have shown that changes occur in $\mathrm{pH}$ levels during the processing of meat products. The $\mathrm{pH}$ level is always lower at the end of the ripening period independently of the presence of yeast. Inoculation with mixed starter cultures (bacteria plus Debaryomyces) resulted in the higher acidification of sausages [73]. However, as previously mentioned, the specific contribution of yeast species cannot be easily deduced due to the presence of bacteria in the starter mix [73]. When $D$. hansenii was used as starter it was difficult to find a general conclusion regarding it effect on the final $\mathrm{pH}$ of the product, although it is possible to state that the consequences of the yeast activity did not acutely affect $\mathrm{pH}$ and that these consequences are strongly dependent on both the yeast strain and product. In some cases, similar $\mathrm{pH}$ values to the control were measured at the end of the process, while in some other studies the final $\mathrm{pH}$ values slightly higher or lower than non-inoculated products were determined $[11,50,54,58]$. In conclusion, few and variable changes in $\mathrm{pH}$ have been reported in yeast-inoculated meat products.

\subsubsection{Water Activity and Moisture}

More homogeneous results were obtained by the different researchers when water activity $\left(A_{w}\right)$ or moisture was determined. It has been fully demonstrated that both parameters decrease along the ripening period in both control and inoculated samples. On the other hand, while higher final values of $\mathrm{A}_{\mathrm{w}}$ were usually measured and explained as a consequence of yeast growth on the product surface $[50,58,65]$, no significant differences in moisture were found when results in control and inoculated products were compared $[11,54,65,73]$.

\subsubsection{Sodium Content}

The possible effects of yeast on the sodium levels of meat products has not been frequently studied. While commercial mixed starter cultures did not affect saltiness of dry-cured foal sausages [74], only in the case of cured pork loins has an effect of $D$. hansenii inoculation on the sodium content of the product been reported [58]. Interestingly, yeast inoculation produced a significant decrease in the sodium content of the product. It is known that $D$. hansenii can accumulate high amounts of sodium from the environment without becoming intoxicated and for this reason it has been defined as a sodium-includer yeast [75-77]. This behaviour may explain why inoculated loins contain lower sodium amounts, a characteristic not previously reported.

\subsubsection{Colour}

Heterogeneous results regarding the consequences of yeast use on this parameter have been reported. On the one hand, the use of $D$. hansenii to inoculate standard slow dry-cured fermented sausages did not affect colour parameters such as redness, yellowness, or lightness [54]. However, the same research group later reported that in the specific case of sausages produced with entirely male fat, yeast inoculation affected colour parameters, 
thus lightness values were significantly higher in the inoculated sausages after 43 days of drying [65].

Once again it is important to keep in mind that many of the effects described depend on the meat product and the manufacturing process followed.

\subsection{Sensory Properties Affected by Debaryomyces hansenii}

We have concluded so far that, on many occasions, the inoculation with Debaryomyces hansenii of various meat products produces significant changes in some of their physicochemical characteristics. A crucial point now is to consider whether all this translates into sensory level changes that are detectable by the consumer

The results of the inoculation of meat products with Debaryomyces on their sensory characteristics are controversial. While some studies have reported significant effects $[67,72]$, other papers showed an absence of sensory effects [42,78]. The authors concluded that results can be affected by the selected strain, the quantity of the inoculated yeast, the type of sausage, the manufacturing process, and even the possible presence of other starters.

\subsubsection{Mixed Starters}

The combination of non-toxigenic moulds and yeasts as starters has been rarely approached. When selected Penicillium chrysogenum and Debaryomyces hansenii strains were inoculated on dry-cured ham, lower levels of some of the main odour-active volatile compounds were measured but not detected by panellists, and a better overall acceptability for inoculated hams was observed and was attributed to their improved texture [48].

In a detailed study, different amounts of Debaryomyces spp. in combination with bacterial starter cultures were used. A final yeast population of $5 \times 10^{6}$ or $15 \times 10^{6} \mathrm{cfu} / \mathrm{g}$ were inoculated in dry-fermented sausages. The sensory analysis showed that the panel significantly preferred the batch with the lower amounts of yeast, but no differences between the control and the $15 \times 10^{6} \mathrm{cfu} / \mathrm{g}$ batches of sausages were found. It was concluded that the yeasts had a positive effect on the sensory characteristics, probably due to the production of ethyl esters that contribute to the proper sausage aroma. It was also concluded that the amount of yeasts present was important, as larger amounts produce a higher generation of acids that may mask the positive effects of Debaryomyces [72].

In a different research, once again $D$. hansenii isolates from natural fermented sausages in combination with bacterial starter cultures were inoculated in slow fermented sausages. In this case, two different $D$. hansenii strains at a final concentration of $1 \times 10^{6} \mathrm{cfu} / \mathrm{g}$ were studied. Although significant differences were measured for the production of volatile compounds, these products were not appreciated by the consumer panel, which was related to the interference of the bacterial starter used in the ripening process [54]. Moreover, the results also pointed out the importance of standardizing the yeast concentration used in each experiment.

\subsubsection{Pure Yeast Starters}

As previously mentioned, the main advantage of using only pure yeasts and not mixed populations of microorganisms as starters is that this provides the possibility of formulating more solid conclusions on the role of a specific strain.

Iucci et al. [67] examined the sensory properties of dry-fermented sausages inoculated with selected D. hansenii D9 or Yarrowia lipolytica Y16 strains. The sensory analysis showed that the sausages inoculated with $D$. hansenii were generally preferred by the panellists, while the inoculation with Y. lipolytica rendered products less appreciated than the control, non-inoculated ones by the group of experts. It is worth mentioning that the degree of mincing affected the sensory properties of the sausages and the necessity of identifying tailor-made yeast starters for each type of sausage and production process was stressed. Later, different biotypes of $D$. hansenii were used to investigate the influence of $D$. hansenii used as single starter culture on the volatile compound generation of dry-fermented sausage "salchichón" and, again, differences between strains were reported [50]. 
In the case of pork loin sample surfaces inoculated with two different amounts of a selected terroir $D$. hansenii strain, the consumer sensory panel did not detect any changes in texture among treatments. However, significant differences were found in all the other attributes evaluated when compared to the control samples. In general, all treatments improved in a similar way the acceptability of the product in comparison to the control, including the aspect of the samples. Moreover, a positive effect with respect to aroma and flavour, and a tendency to higher global consumer acceptability for samples inoculated with higher dose of yeast, was observed. Relevant also was the improvement in the salty taste that the inoculated yeast produced, most probably was due to the sodium-includer characteristics of D. hansenii [58].

Table 2 recapitulates some of the main factors conditioning the effect of $D$. hansenii on the final characteristics of sausages and dry-meat products. In summary, most of the studies highlight the difficulty of obtaining generalized and definitive conclusions on the effects of yeast inoculation on the sensory characteristics of fermented products without a previous and specific study. In some cases, a better consumer acceptance is reported and in some no clear differences are found. Once more, the strains, the amount of yeast, the type of product, or specific manufacturing conditions are crucial to define the possible consequences of the use of a D. hansenii starter.

Table 2. Main factors influencing the effect of Debaryomyces hansenii on the final characteristics of sausages and dry-meat products.

\begin{tabular}{|c|c|}
\hline Factor & Comment \\
\hline Strain & Very heterogeneous behaviour \\
\hline Cell amount inoculated & $\begin{array}{c}\text { The concentration of ufc/g of product greatly } \\
\text { varies in the literature }\end{array}$ \\
\hline Form of application & $\begin{array}{l}\text { Spread on the surface or mixed with the rest of } \\
\text { components of the product }\end{array}$ \\
\hline Presence of additional microbial starters & Presence of bacterial and/or fungal starters \\
\hline Meat product & Acutely diverse meat products \\
\hline Manufacturing conditions & $\begin{array}{l}\text { Time and temperature of ripening, presence of } \\
\text { spices, etc }\end{array}$ \\
\hline
\end{tabular}

\section{Other Debaryomyces hansenii Functions Beyond Just Improving Overall Characteristics of Sausages and Dry-Meat Products}

The meat products mentioned in this review are enormously diverse, both in their origins and in their preparation. However, the steps followed to unravel everything related to the possible role of yeasts in the characteristics of these products are usually highly standardized: first the isolation and identification of yeast genera, followed by a selection of those with the most interesting potential and, finally, the inoculation as a starter and subsequent physicochemical analysis to identify changes in the product.

Much more recently, novel research lines are being opened in order to discover possible additional functions of the yeast population. For example, (i) the inoculation of fermented sausages with Debaryomyces hansenii has been shown to contribute to masking unwanted fat odours due to its lipolytic activities [65,66]; (ii) the potential use of mixed starters containing $D$. hansenii to reduce the risk of meat mutagens and biogenic amines in fermented sausages is being studied [79,80]; or (iii) the efficacy of Debaryomyces hansenii for controlling Listeria monocytogenes has been evaluated in dry-cured ham [81]. In addition, the possible contributions of $D$. hansenii both to reducing preservatives and antimicrobial activities, especially against pathogens, are two research lines of great interest and potential.

\subsection{Counteracting the Negative Impact of Preservatives}

The use of nitrite and nitrate as curing agents in dry-fermented sausages has important technological functions. Nitrite has antioxidant and antimicrobial activities, of which its 
activity against the pathogen Clostridium botulinum and its control of toxin production are the most important. Furthermore, nitrite facilitates the generation and stabilization of the typical colour of the product and enhances the cured flavour [82,83].

An important and actual trend is to reduce the use of nitrite and nitrate in meat products due to the controversy about the adequate amounts of nitrite used as additive in meat products $[84,85]$. However, the consequences of using reduced levels of nitrate and nitrite mixtures on the aroma profile of dry-cured meat products have been scarcely studied. The inoculation of yeasts such as $D$. hansenii, which have the potential to generate desirable aromas in dry-fermented sausages, is a suitable and promising alternative. The effect of the inoculation of a $D$. hansenii strain on dry-fermented sausages manufactured with reduced ingoing amounts of nitrite and nitrate has been very recently evaluated. In a first study, it was reported that different D. hansenii strains showed different abilities to proliferate in media containing nitrate and nitrite and that both substances affected the production of volatile compounds [86]. Later on, the effects of reducing nitrate and nitrite on microbial growth and aroma production during the ripening time were determined in more detail [87]. Nitrite and nitrate reduction in fermented sausages did not affect microbial growth but decreased lipid oxidation and the generation of derived volatiles. $D$. hansenii inoculation limited lipid oxidation and increased the generation of volatile compounds derived from amino acid degradation and esterase activity, and the antioxidant capacity of $D$. hansenii during the drying time prevented nitrite oxidation. It was proposed that, in summary, yeast inoculation counteracts the negative impacts of nitrite and nitrate reduction on aroma due to its antioxidant capacity during drying time, aroma production, and hindering of nitrite oxidation.

Ongoing experiments in the laboratory of the authors provide results that agree with those commented above. In this case, the inoculation of loin pork with a selected strain of $D$. hansenii may allow a reduction in the amounts of preservatives (nitrite/nitrate/salt) used during the applied manufacturing process (not published).

\subsection{Biocontrol of Toxigenic Moulds}

The environmental conditions during the ripening of meat products favour the growth of toxigenic moulds on their surface. Some of these moulds can produce mycotoxins on such meat products. Mycotoxins are secondary fungal metabolites that cause diseases affecting the immune system, nervous system, liver, kidneys, blood, and some mycotoxins are known to be carcinogens [88]. Biocontrol by antagonistic microorganisms has been proposed for controlling toxigenic moulds in foodstuffs. Several research groups have recently focused on the study of the potential role of D. hansenii to control growth and/or the production of mycotoxins by toxigenic moulds in order to minimize this hazard.

Aflatoxins (AFs) and ochratoxin A (OTA) are the two major mycotoxins found in dry-cured meat products (Figure 2). While AFs, produced by several species of Aspergillus such as A. flavus or A. parasiticus, are considered the most toxic, OTA, produced by some Aspergillus and Penicillium species, is the most frequently encountered mycotoxin in drycured meat products, thus their study and control are of fundamental importance.

The mechanisms of action in antifungal yeasts are diverse: (i) competition in the ecosystem [53,89-91]; (ii) production of volatile compounds with antifungal activity [92-95]; and (iii) killer proteins or glycoproteins named mycocins (also known as killer toxins). Mycocins are defined as extracellular proteins with different activities, reportedly with an important main mechanism of action being the inhibition of $\beta$-glucan synthesis in the cell wall of sensitive microorganisms [96-98]. In this respect, once again, the heterogeneity of D. hansenii is very wide [95], however many strains show an antimould effect that does not negatively affect the general characteristics of meat products $[51,99]$. Relatively abundant information in relation to $D$. hansenii and OTA is available. $D$. hansenii can inhibit growth of two ochratoxigenic fungi, $P$. nordicum and P. verrucosum. Additionally, a decrease in OTA production and accumulation in food due to the presence of $D$. hansenii has been reported $[90,91,95,100]$. Very recently, the effect of $D$. hansenii on $A$. westerdijkiae ochratoxin 
A production and growth has been also described [101], however, it is important to mention that when a starter culture containing bacteria plus $D$. hansenii was co-inoculated with $A$. westerdijkiae or P. nordicum in meat-based media, OTA production was stimulated indicating possible unforeseen safety problems [102]. These findings are an important wake-up call regarding the need for specific studies in each case and, in fact, very recently new information indicating that $D$. hansenii reduced the OTA levels produced by P. nordicum in dry-meat products has been provided [99].

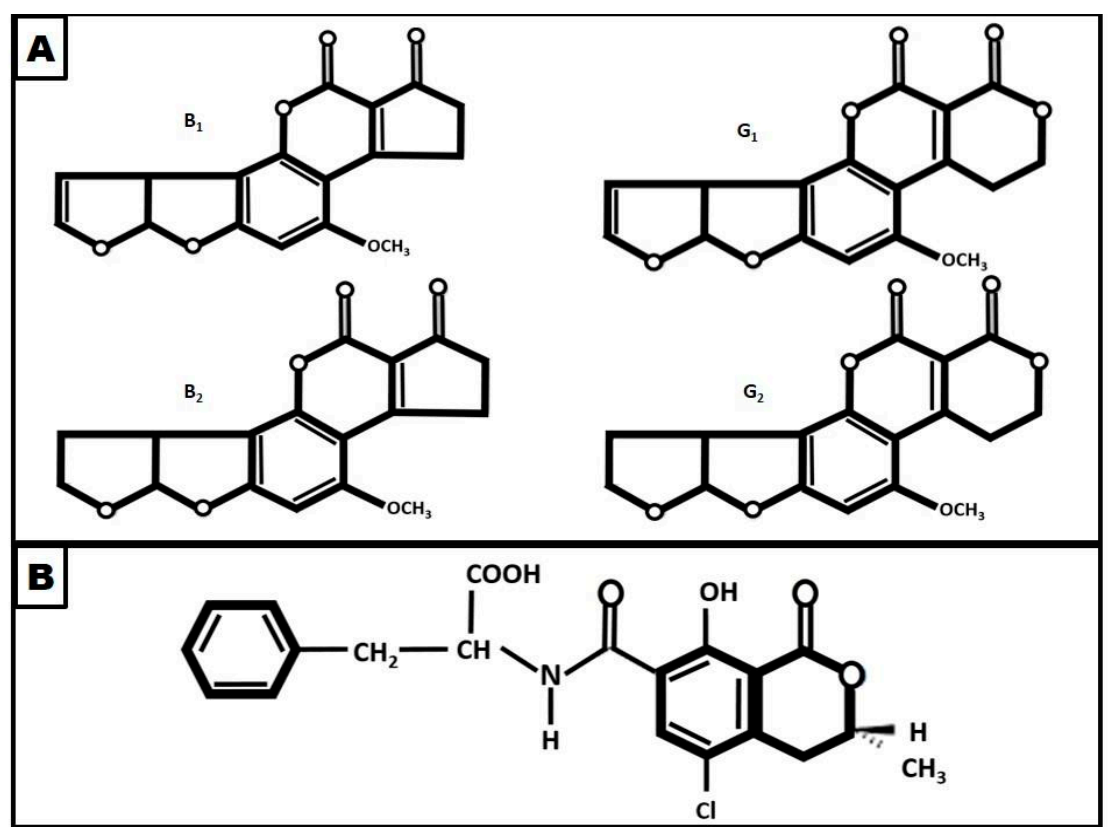

Figure 2. Chemical structure of the mayor mycotoxins found in dry-cured meat products: aflatoxins B1, B2, G1, and G2 (A); and ochratoxin A (B).

Much less information has been published in relation to the potential use of $D$. hansenii selected strains on aflatoxins production. However, the combination of $D$. hansenii and the small antifungal protein, PgAFP, or the use of single native $D$. hansenii strains have been proposed to inhibit the growth of $A$. parasiticus and reduce aflatoxin production in meat products [103,104].

As already mentioned, the mechanisms of action in antifungal yeasts is varied. The effect of antifungal yeasts on the reduction of mycotoxin biosynthesis at the transcriptional level has warranted several studies, although much more research is needed in order to achieve a global view of the field. A repression of the expression of genes involved in OTA biosynthesis has been reported in Aspergillus and Penicillium species as consequence of the presence of $D$. hansenii on yeast-modified Czapek-Dox agar [105], on meat model systems [100], and in dry-cured ham [106]. Therefore, studies related to the effect of yeasts on the gene expression involved in the biosynthetic pathways of mycotoxins would be of utmost interest. This is one of the crucial aims for the future and further investigations focused on the understanding of the different modes of yeast antifungal actions are necessary to enhance and predict the effect of protective cultures of $D$. hansenii on sausages and dry-cured meat products.

Finally, it is worth mentioning that the efficacy of potential biocontrol agents is influenced by both the nutritional sources and inherent environmental factors of the dry-cured meat product processing. The halotolerant character of $D$. hansenii $[17,18]$ makes its application as bio-preservative in dry-cured meat products very adequate due to their salt content. Consequently, it would be interesting to identify the environmental conditions in which the biocontrol agents have the highest effectiveness against the common toxigenic moulds found in these products. In fact, our group has shown that the presence of sodium 
in the external medium improves the performance of $D$. hansenii against different abiotic stresses $[58,107,108]$, and several studies have reports the positive effects of the presence of $\mathrm{NaCl}$ during the use of $D$. hansenii as a biocontrol agent. On the one hand, yeast inhibitory activity of P. nordicum and OTA production was enhanced by the presence of $\mathrm{NaCl}$ [90], and on the other hand a killer toxin produced by $D$. hansenii showed optimum inhibitory effects against different unwanted microorganisms in the presence of $8 \% \mathrm{NaCl}$ [109].

\section{Conclusions and Perspectives}

Debaryomyces hansenii is, most probably, the most abundant yeast found in sausages and dry-meat products manufactured all around the world. However, its specific role on the final characteristics of the products has been controversial. It could be considered a necessary organism or a mere friendly guest. Figure 3 summarizes the multiple consequences that the presence of $D$. hansenii may have on the characteristics of the products. The diversity of meat products, the heterogeneity of the strains, or the multiplicity of manufacturing processes makes impossible to predict what the final result would be after the inoculation of a given meat product with a selected $D$. hansenii strain, at a certain concentration, and under specific conditions, without a preliminary detailed study according to what the industry needs and the consumer demands. From this point of view, it is important to highlight the use of terroir strains and indigenous microbial communities to potentially improve and keep the properties and quality of the products [110].
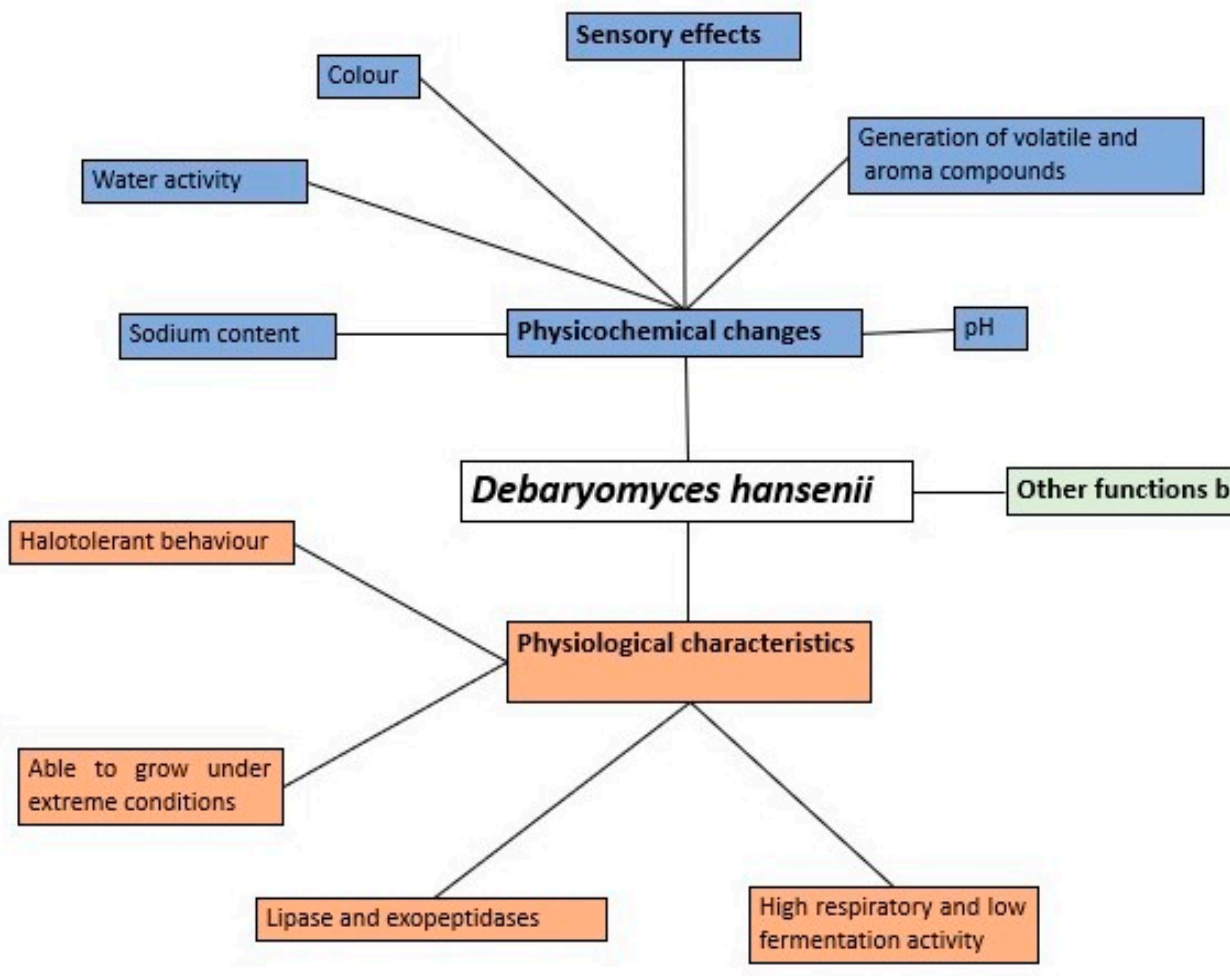

Figure 3. Defining the biological relevance of Debaryomyces hansenii on the final characteristics of sausages and dry-meat products.

What is very conclusive is that there are no reports informing of unwanted negative effects or even health problems due to the inoculation of meat products with $D$. hansenii and, in the worst scenario, the presence of the yeast does not affect the overall quality and typical features of the products.

Globally speaking, the effects of $D$. hansenii on $\mathrm{pH}$, water activity, moisture, or lipid composition are not especially relevant. However, D. hansenii increases carbohydrate fermentation and amino acid catabolism and modifies the levels of volatile and aromatic compounds: it increases the generation of esters such as ethyl esters or alcohol compounds, 
and affects sulphur production. Consequently, there is a tendency to agree that the use of selected strains has a positive effect on final flavour, on the sensory characteristics and, in many cases, on consumer acceptance.

There are important new aspects of research in the field beyond simply improving the general sensory characteristics of sausages and dry-meat products. The contribution of $D$. hansenii on the safety of inoculated sausages and dry-meat products is a subject to be developed in the near future. Global integration and understanding of $D$. hansenii metabolic activities are needed. This yeast is potentially suitable as a bio-preservative agent. $D$. hansenii degrades biogenic amines and its presence may contribute to decreasing the use of some preservatives and strains that inhibit mycotoxins production and unwanted moulds growth.

In conclusion, our knowledge regarding the possibilities of using $D$. hansenii in the manufacturing of meat products is quite extensive, but far from complete. New advances in the study of yeast physiology and molecular biology are likely to bring new insight with both expected and novel impacts in the future. In this sense, the investigation of this yeast as a biocontrol agent or as a tool to obtain more ecological meat products will provide findings directly applicable to the food industry.

Author Contributions: All authors reviewed literature. L.R.-M. and F.R.-P. prepared figures. All authors participated in drafting the manuscript. L.R.-M., F.R.-P., and J.R. revised the manuscript in its final format. All authors approved the final format of the manuscript and its revised versions. All authors have read and agreed to the published version of the manuscript.

Funding: This research was funded by MICIU (Spain) grant number RTI2018-097935-B-I00 and Universidad de Córdoba (Córdoba) grant numbers XX and XXII Plan Propio de Investigación.

Acknowledgments: We thank Carmen Michán (Universidad de Córdoba) for critical reading of the manuscript.

Conflicts of Interest: The authors declare no conflict of interest.

\section{References}

1. Ordóñez, J.A.; Hierro, E.M.; Bruna, J.M.; De La Hoz, L. Changes in the Components of Dry-Fermented Sausages during Ripening. Crit. Rev. Food Sci. Nutr. 1999, 39, 329-367. [CrossRef]

2. Fadda, S.; López, C.; Vignolo, G. Role of lactic acid bacteria during meat conditioning and fermentation: Peptides generated as sensorial and hygienic biomarkers. Meat Sci. 2010, 86, 66-79. [CrossRef]

3. Ravyts, F.; De Vuyst, L.; Leroy, F. Bacterial diversity and functionalities in food fermentations. Eng. Life Sci. 2012, 12, 356-367. [CrossRef]

4. Pasini, F.; Soglia, F.; Petracci, M.; Caboni, M.F.; Marziali, S.; Montanari, C.; Gardini, F.; Grazia, L.; Tabanelli, G. Effect of Fermentation with Different Lactic Acid Bacteria Starter Cultures on Biogenic Amine Content and Ripening Patterns in Dry Fermented Sausages. Nutrients 2018, 10, 1497. [CrossRef]

5. Juárez-Castelán, C.; García-Cano, I.; Escobar-Zepeda, A.; Azaola-Espinosa, A.; Alvarez-Cisneros, Y.M.; Ponce-Alquicira, E. Evaluation of the bacterial diversity of Spanish-type chorizo during the ripening process using high-throughput sequencing and physicochemical characterization. Meat Sci. 2019, 150, 7-13. [CrossRef]

6. Dalton, H.K.; Board, R.G.; Davenport, R.R. The yeasts of British fresh sausage and minced beef. Antonie van Leeuwenhoek 1984, 50, 227-248. [CrossRef] [PubMed]

7. Viljoen, B.; Dykes, G.; Callís, M.; Von Holy, A. Yeasts associated with Vienna sausage packaging. Int. J. Food Microbiol. 1993, 18, 53-62. [CrossRef]

8. Gardini, F.; Suzzi, G.; Lombardi, A.; Galgano, F.; Crudele, M.A.; Andrighetto, C.; Schirone, M.; Tofalo, R. A survey of yeasts in traditional sausages of southern Italy. FEMS Yeast Res. 2001, 1, 161-167. [CrossRef]

9. Cocolin, L.; Urso, R.; Rantsiou, K.; Cantoni, C.; Comi, G. Dynamics and characterization of yeasts during natural fermentation of Italian sausages. FEMS Yeast Res. 2006, 6, 692-701. [CrossRef]

10. Chen, L.; Wang, Z.; Ji, L.; Zhang, J.; Zhao, Z.; Zhang, R.; Bai, T.; Hou, B.; Wang, W. Flavor Composition and Microbial Community Structure of Mianning Ham. Front. Microbiol. 2021, 11, 623775. [CrossRef]

11. Dura, M. Effect of growth phase and dry-cured sausage processing conditions on Debaryomyces spp. generation of volatile compounds from branched-chain amino acids. Food Chem. 2004, 86, 391-399. [CrossRef]

12. Coppola, S.; Mauriello, G.; Aponte, M.; Moschetti, G.; Villani, F. Microbial succession during ripening of Naples-type salami, a southern Italian fermented sausage. Meat Sci. 2000, 56, 321-329. [CrossRef] 
13. Encinas, J.-P.; López-Díaz, T.-M.; García-López, M.-L.; Otero, A.; Moreno, B. Yeast populations on Spanish fermented sausages. Meat Sci. 2000, 54, 203-208. [CrossRef]

14. Aquilanti, L.; Santarelli, S.; Silvestri, G.; Osimani, A.; Petruzzelli, A.; Clementi, F. The microbial ecology of a typical Italian salami during its natural fermentation. Int. J. Food Microbiol. 2007, 120, 136-145. [CrossRef]

15. Mendonça, R.C.; Gouvêa, D.M.; Hungaro, H.M.; Sodré, A.D.F.; Querol, A. Dynamics of the yeast flora in artisanal country style and industrial dry cured sausage (yeast in fermented sausage). Food Control. 2013, 29, 143-148. [CrossRef]

16. García-Béjar, B.; Sánchez-Carabias, D.; Alarcon, M.; Arévalo-Villena, M.; Briones, A. Autochthonous Yeast from Pork and Game Meat Fermented Sausages for Application in Meat Protection and Aroma Developing. Animals 2020, 10, 2340. [CrossRef] [PubMed]

17. Prista, C.; Michan, C.; Miranda, I.M.; Ramos, J. The halotolerant Debaryomyces hansenii, the Cinderella of non-conventional yeasts. Yeast 2016, 33, 523-533. [CrossRef] [PubMed]

18. Breuer, U.; Harms, H. Debaryomyces hansenii-An extremophilic yeast with biotechnological potential. Yeast 2006, 23, 415-437. [CrossRef] [PubMed]

19. Sánchez, N.S.; Calahorra, M.; González-Hernández, J.C.; Peña, A. Glycolytic sequence and respiration of Debaryomyces hansenii as compared to Saccharomyces cerevisiae. Yeast 2006, 23, 361-374. [CrossRef]

20. Gonzalez-Hernandez, J.C.; Jiménez-Estrada, M.; Pena, A. Comparative analysis of trehalose production by Debaryomyces hansenii and Saccharomyces cerevisiae under saline stress. Extremophiles 2005, 9, 7-16. [CrossRef]

21. Navarrete, C.; Frost, A.T.; Ramos-Moreno, L.; Krum, M.R.; Martínez, J.L. A physiological characterization in controlled bioreactors reveals a novel survival strategy for Debaryomyces hansenii at high salinity. Yeast 2021, 38, 302-315. [CrossRef] [PubMed]

22. Carvalheiro, F.; Duarte, L.C.; Lopes, S.; Parajó, J.C.; Pereira, H.; Gírio, F.M. Supplementation requirements of brewery's spent grain hydrolysate for biomass and xylitol production by Debaryomyces hansenii CCMI 941. J. Ind. Microbiol. Biotechnol. 2006, 33, 646-654. [CrossRef] [PubMed]

23. Axelson-Fisk, M.; Sunnerhagen, P. Comparative genomics and gene finding in fungi. In Methods in Molecular Biology; Springer: Berlin/Heidelberg, Germany, 2006; Volume 15, pp. 1-28.

24. Corredor, M.; Davila, A.-M.; Casarégola, S.; Gaillardin, C. Chromosomal polymorphism in the yeast species Debaryomyces hansenii. Antonie van Leeuwenhoek 2003, 84, 81-88. [CrossRef] [PubMed]

25. Quirós, M.; Wrent, P.; Valderrama, M.-J.; De Silóniz, M.-I.; Peinado, J.M. A ß-Glucuronidase-Based Agar Medium for the Differential Detection of the Yeast Debaryomyces hansenii from Foods. J. Food Prot. 2005, 68, 808-814. [CrossRef]

26. Martorell, P.; Fernández-Espinar, M.T.; Querol, A. Sequence-based identification of species belonging to the genus Debaryomyces FEMS Yeast Res. 2005, 5, 1157-1165. [CrossRef] [PubMed]

27. Andrade, M.J.; Rodriguez, M.; Sanchez, B.; Aranda, E.; Córdoba, J. DNA typing methods for differentiation of yeasts related to dry-cured meat products. Int. J. Food Microbiol. 2006, 107, 48-58. [CrossRef]

28. Romano, P.; Capece, A.; Jespersen, L. Taxonomic and Ecological Diversity of Food and Beverage Yeasts; Springer: Berlin/Heidelberg, Germany, 2006; pp. 13-53.

29. Ramos, J.; Melero, Y.; Ramos-Moreno, L.; Michán, C.; Cabezas, L. Debaryomyces hansenii Strains from Valle De Los Pedroches Iberian Dry Meat Products: Isolation, Identification, Characterization, and Selection for Starter Cultures. J. Microbiol. Biotechnol. 2017, 27, 1576-1585. [CrossRef]

30. Desnos-Ollivier, M.; Ragon, M.; Robert, V.; Raoux, D.; Gantier, J.-C.; Dromer, F. Debaryomyces hansenii (Candida famata), a Rare Human Fungal Pathogen Often Misidentified as Pichia guilliermondii (Candida guilliermondii). J. Clin. Microbiol. 2008, 46, 3237-3242. [CrossRef]

31. Cornet, M.; Sendid, B.; Fradin, C.; Gaillardin, C.; Poulain, D.; Nguyen, H.-V. Molecular Identification of Closely Related Candida Species Using Two Ribosomal Intergenic Spacer Fingerprinting Methods. J. Mol. Diagn. 2011, 13, 12-22. [CrossRef]

32. Castanheira, M.; Woosley, L.; Diekema, D.; Jones, R.N.; Pfaller, M. Candida guilliermondii and Other Species of Candida Misidentified as Candida famata: Assessment by Vitek 2, DNA Sequencing Analysis, and Matrix-Assisted Laser Desorption Ionization-Time of Flight Mass Spectrometry in Two Global Antifungal Surveillance Programs. J. Clin. Microbiol. 2012, 51, 117-124. [CrossRef]

33. Jacques, N.; Mallet, S.; Casaregola, S. Delimitation of the species of the Debaryomyces hansenii complex by intron sequence analysis. Int. J. Syst. Evol. Microbiol. 2009, 59, 1242-1251. [CrossRef] [PubMed]

34. Santos, M.; Gomes, A.C.; Santos, M.C.; Carreto, L.C.; Moura, G. The genetic code of the fungal CTG clade. Comptes Rendus Biol. 2011, 334, 607-611. [CrossRef]

35. Cappriotti, A. Indagini Microbiologiche Sulle Carni Insaccate. Nota I: I Lieviti. Arch. Vet. Ital. 1954, 5, $113-117$.

36. Samelis, J.; Maurogenakis, F.; Metaxopoulos, J. Characterisation of lactic acid bacteria isolated from naturally fermented Greek dry salami. Int. J. Food Microbiol. 1994, 23, 179-196. [CrossRef]

37. Núñez, F.; Rodríguez, M.; Córdoba, J.J.; Bermúdez, E.; Asensio, M.A. Yeast population during ripening of dry-cured Iberian ham. Int. J. Food Microbiol. 1996, 29, 271-280. [CrossRef]

38. Baruzzi, F.; Matarante, A.; Caputo, L.; Morea, M. Molecular and physiological characterization of natural microbial communities isolated from a traditional Southern Italian processed sausage. Meat Sci. 2006, 72, 261-269. [CrossRef]

39. Ozturk, I.; Sagdic, O. Biodiversity of Yeast Mycobiota in "Sucuk," a Traditional Turkish Fermented Dry Sausage: Phenotypic and Genotypic Identification, Functional and Technological Properties. J. Food Sci. 2014, 79, M2315-M2322. [CrossRef] [PubMed] 
40. Martínez-Onandi, N.; Sánchez, C.; Nuñez, M.; Picon, A. Microbiota of Iberian dry-cured ham as influenced by chemical composition, high pressure processing and prolonged refrigerated storage. Food Microbiol. 2019, 80, 62-69. [CrossRef]

41. Belleggia, L.; Milanović, V.; Ferrocino, I.; Cocolin, L.; Haouet, M.N.; Scuota, S.; Maoloni, A.; Garofalo, C.; Cardinali, F.; Aquilanti, L.; et al. Is there any still undisclosed biodiversity in Ciauscolo salami? A new glance into the microbiota of an artisan production as revealed by high-throughput sequencing. Meat Sci. 2020, 165, 108128. [CrossRef]

42. Olesen, P.T.; Stahnke, L.H. The influence of Debaryomyces hansenii and Candida utilis on the aroma formation in garlic spiced fermented sausages and model minces. Meat Sci. 2000, 56, 357-368. [CrossRef]

43. Asefa, D.T.; Møretrø, T.; Gjerde, R.O.; Langsrud, S.; Kure, C.F.; Sidhu, M.S.; Nesbakken, T.; Skaar, I. Yeast diversity and dynamics in the production processes of Norwegian dry-cured meat products. Int. J. Food Microbiol. 2009, 133, 135-140. [CrossRef]

44. Belleggia, L.; Ferrocino, I.; Reale, A.; Boscaino, F.; Di Renzo, T.; Corvaglia, M.R.; Cocolin, L.; Milanović, V.; Cardinali, F.; Garofalo, C.; et al. Portuguese cacholeira blood sausage: A first taste of its microbiota and volatile organic compounds. Food Res. Int. 2020, 136, 109567. [CrossRef]

45. Mendoza, L.M.; Padilla, B.; Belloch, C.; Vignolo, G. Diversity and enzymatic profile of yeasts isolated from traditional llama meat sausages from north-western Andean region of Argentina. Food Res. Int. 2014, 62, 572-579. [CrossRef]

46. Lin, F.; Cai, F.; Luo, B.; Gu, R.; Ahmed, S.; Long, C. Variation of Microbiological and Biochemical Profiles of Laowo Dry-Cured Ham, an Indigenous Fermented Food, during Ripening by GC-TOF-MS and UPLC-QTOF-MS. J. Agric. Food Chem. 2020, 68, 8925-8935. [CrossRef]

47. Mu, Y.; Su, W.; Mu, Y.; Jiang, L. Combined Application of High-Throughput Sequencing and Metabolomics Reveals Metabolically Active Microorganisms During Panxian Ham Processing. Front. Microbiol. 2020, 10, 3012. [CrossRef]

48. Martín, A.; Córdoba, J.J.; Aranda, E.; Cordoba, M.D.G.; A Asensio, M. Contribution of a selected fungal population to the volatile compounds on dry-cured ham. Int. J. Food Microbiol. 2006, 110, 8-18. [CrossRef] [PubMed]

49. Purriños, L.; Carballo, J.; Lorenzo, J.M. The Influence of Debaryomyces hansenii, Candida deformans and Candida zeylanoides on the aroma formation of dry-cured "lacón. " Meat Sci. 2013, 93, 344-350. [CrossRef] [PubMed]

50. Andrade, M.J.; Córdoba, J.J.; Casado, E.M.; Cordoba, M.D.G.; Rodríguez, M. Effect of selected strains of Debaryomyces hansenii on the volatile compound production of dry fermented sausage "salchichón". Meat Sci. 2010, 85, 256-264. [CrossRef]

51. Murgia, M.A.; Marongiu, A.; Aponte, M.; Blaiotta, G.; Deiana, P.; Mangia, N.P. Impact of a selected Debaryomyces hansenii strain's inoculation on the quality of Sardinian fermented sausages. Food Res. Int. 2019, 121, 144-150. [CrossRef] [PubMed]

52. Villani, F.; Casaburi, A.; Pennacchia, C.; Filosa, L.; Russo, F.; Ercolini, D. Microbial Ecology of the Soppressata of Vallo di Diano, a Traditional Dry Fermented Sausage from Southern Italy, and In Vitro and In Situ Selection of Autochthonous Starter Cultures. Appl. Environ. Microbiol. 2007, 73, 5453-5463. [CrossRef]

53. Simoncini, N.; Virgili, R.; Spadola, G.; Battilani, P. Autochthonous yeasts as potential biocontrol agents in dry-cured meat products. Food Control. 2014, 46, 160-167. [CrossRef]

54. Cano-García, L.; Belloch, C.; Flores, M. Impact of Debaryomyces hansenii strains inoculation on the quality of slow dry-cured fermented sausages. Meat Sci. 2014, 96, 1469-1477. [CrossRef]

55. Cano-García, L.; Rivera-Jiménez, S.; Belloch, C.; Flores, M. Generation of aroma compounds in a fermented sausage meat model system by Debaryomyces hansenii strains. Food Chem. 2014, 151, 364-373. [CrossRef] [PubMed]

56. Martín, A.; Asensio, M.A.; Bermúdez, E.; Cordoba, M.D.G.; Aranda, E.; Córdoba, J.J. Proteolytic activity of Penicillium chrysogenum and Debaryomyces hansenii during controlled ripening of pork loins. Meat Sci. 2002, 62, 129-137. [CrossRef]

57. Martín, A.; Córdoba, J.J.; Benito, M.J.; Aranda, E.; Asensio, M.A. Effect of Penicillium chrysogenum and Debaryomyces hansenii on the volatile compounds during controlled ripening of pork loins. Int. J. Food Microbiol. 2003, 84, 327-338. [CrossRef]

58. Ramos-Moreno, L.; Castilla, F.J.R.; Bravo, C.; Martínez, E.; Menéndez, M.; Dios-Palomares, R.; Ramos, J. Inoculation with a terroir selected Debaryomyces hansenii strain changes physico-chemical characteristics of Iberian cured pork loin. Meat Sci. 2019, 157, 107875. [CrossRef] [PubMed]

59. Metaxopoulos, J.; Stavropoulos, S.; Kakouri, A.; Samelis, J. Yeasts Isolated from Traditional Greek Dry Salami. Ital. J. Food Sci. 1996, 8, 25-32.

60. Samelis, J. Stability and safety of traditional Greek salami-A microbiological ecology study. Int. J. Food Microbiol. 1998, 44, 69-82. [CrossRef]

61. Lücke, F.-K. Fermented sausages. In Microbiology of Fermented Foods; Springer: Berlin/Heidelberg, Germany, 1998 ; pp. $441-483$.

62. Leistner, L. Allgemeines Über Rohwurst. Fleischwirtschaft 1986, 66, 290-300.

63. Flores, M.; Corral, S.; Cano-García, L.; Salvador, A.; Belloch, C. Yeast strains as potential aroma enhancers in dry fermented sausages. Int. J. Food Microbiol. 2015, 212, 16-24. [CrossRef]

64. Corral, S.; Salvador, A.; Flores, M. Salt reduction in slow fermented sausages affects the generation of aroma active compounds. Meat Sci. 2013, 93, 776-785. [CrossRef] [PubMed]

65. Corral, S.; Belloch, C.; López-Díez, J.J.; Salvador, A.; Flores, M. Yeast inoculation as a strategy to improve the physico-chemical and sensory properties of reduced salt fermented sausages produced with entire male fat. Meat Sci. 2017, 123, 1-7. [CrossRef] [PubMed]

66. Corral, S.; Belloch, C.; López-Díez, J.J.; Flores, M. Lipolysis and aroma generation as mechanisms involved in masking boar taint in sodium reduced fermented sausages inoculated with Debaryomyces hansenii yeast. J. Sci. Food Agric. 2017, 98, 2121-2130. [CrossRef] 
67. Iucci, L.; Patrignani, F.; Belletti, N.; Ndagijimana, M.; Guerzoni, M.E.; Gardini, F.; Lanciotti, R. Role of surface-inoculated Debaryomyces hansenii and Yarrowia lipolytica strains in dried fermented sausage manufacture. Part 2: Evaluation of their effects on sensory quality and biogenic amine content. Meat Sci. 2007, 75, 669-675. [CrossRef]

68. Patrignani, F.; Iucci, L.; Vallicelli, M.; Guerzoni, M.E.; Gardini, F.; Lanciotti, R. Role of surface-inoculated Debaryomyces hansenii and Yarrowia lipolytica strains in dried fermented sausage manufacture. Part 1: Evaluation of their effects on microbial evolution, lipolytic and proteolytic patterns. Meat Sci. 2007, 75, 676-686. [CrossRef] [PubMed]

69. Sørensen, B.B. The combined effects of temperature, $\mathrm{pH}$ and $\mathrm{NaCl}$ on growth of Debaryomyces hansenii analyzed by flow cytometry and predictive microbiology. Int. J. Food Microbiol. 1997, 34, 209-220. [CrossRef]

70. Cano-García, L.; Flores, M.; Belloch, C. Molecular characterization and aromatic potential of Debaryomyces hansenii strains isolated from naturally fermented sausages. Food Res. Int. 2013, 52, 42-49. [CrossRef]

71. Perea-Sanz, L.; Peris, D.; Belloch, C.; Flores, M. Debaryomyces hansenii Metabolism of Sulfur Amino Acids As Precursors of Volatile Sulfur Compounds of Interest in Meat Products. J. Agric. Food Chem. 2019, 67, 9335-9343. [CrossRef]

72. Flores, M.; Durá, M.-A.; Marco, A.; Toldrá, F. Effect of Debaryomyces spp. on aroma formation and sensory quality of dryfermented sausages. Meat Sci. 2004, 68, 439-446. [CrossRef]

73. Lorenzo, J.M.; Gómez, M.; Purriños, L.; Fonseca, S.; Rodriguez, J.M.L. Effect of commercial starter cultures on volatile compound profile and sensory characteristics of dry-cured foal sausage. J. Sci. Food Agric. 2015, 96, 1194-1201. [CrossRef] [PubMed]

74. Lorenzo, J.M.; Gómez, M.; Fonseca, S. Effect of commercial starter cultures on physicochemical characteristics, microbial counts and free fatty acid composition of dry-cured foal sausage. Food Control. 2014, 46, 382-389. [CrossRef]

75. Prista, C.; Almagro, A.; Loureiro-Dias, M.C.; Ramos, J. Physiological basis for the high salt tolerance of Debaryomyces hansenii. Appl. Environ. Microbiol. 1997, 63, 4005-4009. [CrossRef] [PubMed]

76. Martínez, J.L.; Sychrova, H.; Ramos, J. Monovalent cations regulate expression and activity of the Hak1 potassium transporter in Debaryomyces hansenii. Fungal Genet. Biol. 2011, 48, 177-184. [CrossRef]

77. Herrera, R.; Salazar, A.; Ramos-Moreno, L.; Ruiz-Roldan, C.; Ramos, J. Vacuolar control of subcellular cation distribution is a key parameter in the adaptation of Debaryomyces hansenii to high salt concentrations. Fungal Genet. Biol. 2017, 100, 52-60. [CrossRef]

78. Selgas, M.D.; Ros, J.; García, M.L. Effect of selected yeast strains on the sensory properties of dry fermented sausages. Eur. Food Res. Technol. 2003, 217, 475-480. [CrossRef]

79. Kim, H.S.; Lee, S.Y.; Kang, H.J.; Joo, S.-T.; Hur, S.J. Effects of Six Different Starter Cultures on Mutagenicity and Biogenic Amine Concentrations in Fermented Sausages Treated with Vitamins C and E. Food Sci. Anim. Resour. 2019, 39, 877-887. [CrossRef]

80. Laranjo, M.; Potes, M.E.; Elias, M. Role of Starter Cultures on the Safety of Fermented Meat Products. Front. Microbiol. 2019, 10, 853. [CrossRef]

81. Alía, A.; Córdoba, J.J.; Rodríguez, A.; García, C.; Andrade, M.J. Evaluation of the efficacy of Debaryomyces hansenii as protective culture for controlling Listeria monocytogenes in sliced dry-cured ham. LWT 2020, 119, 108886. [CrossRef]

82. Honikel, K.-O. The use and control of nitrate and nitrite for the processing of meat products. Meat Sci. 2008, 78, 68-76. [CrossRef] [PubMed]

83. Sindelar, J.; Milkowski, A. Sodium Nitrite in Processed Meat and Poultry Meats: A Review of Curin and Examining the Risk and Benefit of Its Use. White Pap. Ser. No 2011, 3, 1-14.

84. De Maere, H.; Fraeye, I.; De Mey, E.; Dewulf, L.; Michiels, C.; Paelinck, H.; Chollet, S. Formation of naturally occurring pigments during the production of nitrite-free dry fermented sausages. Meat Sci. 2016, 114, 1-7. [CrossRef] [PubMed]

85. De Mey, E.; De Maere, H.; Paelinck, H.; Fraeye, I. VolatileN-nitrosamines in meat products: Potential precursors, influence of processing, and mitigation strategies. Crit. Rev. Food Sci. Nutr. 2017, 57, 2909-2923. [CrossRef] [PubMed]

86. Flores, M.; Moncunill, D.; Montero, R.; López-Díez, J.J.; Belloch, C. Screening of Debaryomyces hansenii Strains for Flavor Production under a Reduced Concentration of Nitrifying Preservatives Used in Meat Products. J. Agric. Food Chem. 2017, 65, 3900-3909. [CrossRef] [PubMed]

87. Perea-Sanz, L.; López-Díez, J.J.; Belloch, C.; Flores, M. Counteracting the effect of reducing nitrate/nitrite levels on dry fermented sausage aroma by Debaryomyces hansenii inoculation. Meat Sci. 2020, 164, 108103. [CrossRef] [PubMed]

88. Ben Taheur, F.; Kouidhi, B.; Al Qurashi, Y.M.A.; Ben Salah-Abbès, J.; Chaieb, K. Review: Biotechnology of mycotoxins detoxification using microorganisms and enzymes. Toxicon 2019, 160, 12-22. [CrossRef]

89. Droby, S.; Chalutz, E.; Wilson, C.L.; Wisniewski, M. Characterization of the biocontrol activity of Debaryomyces hansenii in the control of Penicillium digitatum on grapefruit. Can. J. Microbiol. 1989, 35, 794-800. [CrossRef]

90. Virgili, R.; Simoncini, N.; Toscani, T.; Leggieri, M.C.; Formenti, S.; Battilani, P. Biocontrol of Penicillium nordicum Growth and Ochratoxin A Production by Native Yeasts of Dry Cured Ham. Toxins 2012, 4, 68-82. [CrossRef]

91. Andrade, M.J.; Thorsen, L.; Rodriguez, A.; Córdoba, J.J.; Jespersen, L. Inhibition of ochratoxigenic moulds by Debaryomyces hansenii strains for biopreservation of dry-cured meat products. Int. J. Food Microbiol. 2014, 170, 70-77. [CrossRef]

92. Taczman-Brückner, A.; Mohácsi-Farkas, C.; Balla, C.; Kiskó, G. Comparison of biocontrol activity ofKluyveromyces lactiswith other yeast strains againstPenicillium expansum. Acta Aliment. 2005, 34, 71-80. [CrossRef]

93. Taczman-Brückner, A.; Mohácsi-Farkas, C.; Balla, C.; Kiskó, G. Mode of action of Kluyveromyces lactis in biocontrol of Penicillium expansum. Acta Aliment. 2005, 34, 153-160. [CrossRef] 
94. Masoud, W.; Poll, L.; Jakobsen, M. Influence of volatile compounds produced by yeasts predominant during processing ofCoffea arabica in East Africa on growth and ochratoxin A (OTA) production byAspergillus ochraceus. Yeast 2005, 22, 1133-1142. [CrossRef] [PubMed]

95. Núñez, F.; Lara, M.S.; Peromingo, B.; Delgado, J.; Sánchez-Montero, L.; Andrade, M.J. Selection and evaluation of Debaryomyces hansenii isolates as potential bioprotective agents against toxigenic penicillia in dry-fermented sausages. Food Microbiol. 2015, 46, 114-120. [CrossRef]

96. Hernández, A.; Martín, A.; Cordoba, M.D.G.; Benito, M.J.; Aranda, E.; Pérez-Nevado, F. Determination of killer activity in yeasts isolated from the elaboration of seasoned green table olives. Int. J. Food Microbiol. 2008, 121, 178-188. [CrossRef]

97. Coelho, A.R.; Tachi, M.; Pagnocca, F.C.; Nobrega, G.M.A.; Hoffmann, F.L.; Harada, K.-I.; Hirooka, E.Y. Purification of Candida guilliermondii and Pichia ohmerikiller toxin as an active agent against Penicillium expansum. Food Addit. Contam. Part A 2009, 26, 73-81. [CrossRef] [PubMed]

98. Tay, S.-T.; Lim, S.-L.; Tan, H.-W. Growth inhibition of Candida species by Wickerhamomyces anomalus mycocin and a lactone compound of Aureobasidium pullulans. BMC Complement. Altern. Med. 2014, 14, 439. [CrossRef] [PubMed]

99. Álvarez, M.M.; Núñez, F.; Delgado, J.; Andrade, M.J.; Rodríguez, M.; Rodríguez, A. Competitiveness of three biocontrol candidates against ochratoxigenic Penicillium nordicum under dry-cured meat environmental and nutritional conditions. Fungal Biol. 2021, 125, 134-142. [CrossRef] [PubMed]

100. Peromingo, B.; Núñez, F.; Rodriguez, A.; Alía, A.; Andrade, M.J. Potential of yeasts isolated from dry-cured ham to control ochratoxin A production in meat models. Int. J. Food Microbiol. 2018, 268, 73-80. [CrossRef]

101. Iacumin, L.; Arnoldi, M.; Comi, G. Effect of a Debaryomyces hansenii and Lactobacillus buchneri Starter Culture on Aspergillus westerdijkiae Ochratoxin A Production and Growth during the Manufacture of Short Seasoned Dry-Cured Ham. Microorganisms 2020, 8, 1623. [CrossRef]

102. Meftah, S.; Abid, S.; Dias, T.; Rodrigues, P. Effect of dry-sausage starter culture and endogenous yeasts on Aspergillus westerdijkiae and Penicillium nordicum growth and OTA production. LWT 2018, 87, 250-258. [CrossRef]

103. Delgado, J.; Rodríguez, A.; Garcia-Sanchez, A.; Núñez, F.; Asensio, M.A. Inhibitory Effect of PgAFP and Protective Cultures on Aspergillus parasiticus Growth and Aflatoxins Production on Dry-Fermented Sausage and Cheese. Microorganisms 2018, 6, 69. [CrossRef]

104. Peromingo, B.; Andrade, M.J.; Delgado, J.; Sánchez-Montero, L.; Núñez, F. Biocontrol of aflatoxigenic Aspergillus parasiticus by native Debaryomyces hansenii in dry-cured meat products. Food Microbiol. 2019, 82, 269-276. [CrossRef] [PubMed]

105. Gil-Serna, J.; Patiño, B.; Cortes, L.; González-Jaén, M.T.; Vázquez, C. Mechanisms involved in reduction of ochratoxin A produced by Aspergillus westerdijkiae using Debaryomyces hansenii CYC 1244. Int. J. Food Microbiol. 2011, 151, 113-118. [CrossRef]

106. Cebrián, E.; Rodríguez, M.; Peromingo, B.; Bermúdez, E.; Núñez, F. Efficacy of the Combined Protective Cultures of Penicillium chrysogenum and Debaryomyces hansenii for the Control of Ochratoxin A Hazard in Dry-Cured Ham. Toxins 2019, 11, 710. [CrossRef]

107. Almagro, A.; Prista, C.; Castro, S.; Quintas, C.; Madeira-Lopes, A.; Ramos, J.; Loureiro-Dias, M.C. Effects of salts on Debaryomyces hansenii and Saccharomyces cerevisiae under stress conditions. Int. J. Food Microbiol. 2000, 56, 191-197. [CrossRef]

108. Michan, C.; Martínez, J.L.; Alvarez, M.C.; Turk, M.; Sychrova, H.; Ramos, J. Salt and oxidative stress tolerance inDebaryomyces hanseniiandDebaryomyces fabryi. FEMS Yeast Res. 2012, 13, 180-188. [CrossRef]

109. Al-Qaysi, S.A.S.; H, H.A.-H.; Thabit, Z.A.; Al-Kubaisy, W.H.A.A.-R.; Ibrahim, J.A.A.-R. Production, Characterization, and Antimicrobial Activity of Mycocin Produced byDebaryomyces hanseniiDSMZ70238. Int. J. Microbiol. 2017, 2017, 1-9. [CrossRef] [PubMed]

110. Prpich, N.Z.P.; Camprubí, G.E.; Cayré, M.E.; Castro, M.P. Indigenous Microbiota to Leverage Traditional Dry Sausage Production. Int. J. Food Sci. 2021, 2021, 1-15. [CrossRef] [PubMed] 